\title{
Changes in species composition in alpine snowbeds with climate change inferred from small-scale spatial patterns
}

\author{
Christian Schöb, Peter M. Kammer, Zaal Kikvidze, Philippe Choler and Heinz Veit
}

Schöb, C., Kammer, P. M., Kikvidze, Z., Choler, P. and Veit, H. 2008. Changes in species composition in alpine snowbeds with climate change inferred from small-scale spatial patterns. - Web Ecol. 8: 142-159.

Alpine snowbeds are characterised by a very short growing season. However, the length of the snow-free period is increasingly prolonged due to climate change, so that snowbeds become susceptible to invasions from neighbouring alpine meadow communities. We hypothesised that spatial distribution of species generated by plant interactions may indicate whether snowbed species will coexist with or will be out-competed by invading alpine species - spatial aggregation or segregation will point to coexistence or competitive exclusion, respectively. We tested this hypothesis in snowbeds of the Swiss Alps using the variance ratio statistics. We focused on the relationships between dominant snowbed species, subordinate snowbed species, and potentially invading alpine grassland species.

Subordinate snowbed species were generally spatially aggregated with each other, but were segregated from alpine grassland species. Competition between alpine grassland and subordinate snowbed species may have caused this segregation. Segregation between these species groups increased with earlier snowmelt, suggesting an increasing importance of competition with climate change. Further, a dominant snowbed species (Alchemilla pentaphyllea) was spatially aggregated with subordinate snowbed species, while two other dominants (Gnaphalium supinum and Salix herbacea) showed aggregated patterns with alpine grassland species. These dominant species are known to show distinct microhabitat preferences suggesting the existence of hidden microhabitats with different susceptibility to invaders.

These results allow us to suggest that alpine snowbed areas are likely to be reduced as a consequence of climate change and that invading species from nearby alpine grasslands could outcompete subordinate snowbed species. On the other hand, microhabitats dominated by Gnaphalium or Salix seem to be particularly prone to invasions by nonsnowbed species.

C. Schöb (christian.schoeb@phbern.ch), Inst.of Geography,Univ.of Bern, Hallerstrasse 12, CH-3012 Bern, Switzerland. - P. M. Kammer, Biology Dept, Univ. of Teacher Education, Gertrud-Woker-Strasse 5, CH-3012 Bern, Switzerland. - Z. Kikvidze, 568 Environmental Bldg., Univ. of Tokyo, 5-1-5 Kashiwanoha, Kashiwa, JP-277-8653 Chiba, Japan. - P. Choler, Laboratoire d'Ecologie Alpine UMR 5553 UJF-CNRS and Station Alpine J. Fourier UMS 2925 UJF-CNRS, Univ. of Grenoble, FR-38041 Grenoble, France. PC also at: CSIRO Marine and Atmospheric Research, PO Box 1666, Canberra, ACT 2601, Australia. - H. Veit, Inst. of Geography, Univ. of Bern, Hallerstrasse 12, CH-3012 Bern, Switzerland.

Accepted 26 November 2008

Copyright (C) EEF

ISSN 1399-1183 
Climate change will cause a considerable response in alpine vegetation (Theurillat and Guisan 2001). Changes in species composition can be observed already. For example, in alpine grasslands Keller et al. (2000) found an increase in species with higher thermal demands at the expense of species preferring low thermal conditions. Other studies observed an expansion of shrubs within the alpine zone (Kullman 2002, Cannone et al. 2007). Moreover, local extinctions of species are predicted for the future (Guisan and Theurillat 2000, Thuiller et al. 2005).

Alpine snowbeds are considered a model plant community for studying the consequences of climate change in alpine vegetation (Björk and Molau 2007). They are characterised by a long lasting snow cover (Billings and Bliss 1959), but snow cover duration is expected to shorten due to climate change (Beniston et al. 2003). Therefore, the current characteristic vegetation of snowbeds, usually composed by a dense carpet of tiny plants containing several endemic species specialised to this extreme habitat (Tomaselli 1991, Choler 2005, Schöb et al. 2009), may change. The predicted advance of snowmelt in the spring threatens snowbed communities with invasion of non-specialised species from neighbouring alpine communities, such as Carex curvula or Nardus stricta originating from alpine grasslands (Grabherr 2003). The consequences of this invasion of alpine non-snowbed species on snowbed vegetation may depend on the plant-plant interactions that predominate in snowbeds (Heegaard and Vandvik 2004); facilitative interactions between snowbed species and invading alpine grassland species may promote coexistence, whereas competition between them may lead to replacement and local extinction of the least competitive species.

The type of interactions that predominate within plant communities can be revealed by analyses of spatial patterns (Badano et al. 2005, Kikvidze et al. 2005b) assuming that there are no abiotic differences causing nonrandom distribution of species, although even small-scale environmental heterogeneity can induce spatial patterns within communities (Seabloom et al. 2005). For example, Thiéry et al. (1995) showed how slight gradients in topography and the associated gradual flow of water could be responsible for striped vegetation patterns in arid zones, where densely vegetated bands alternated regularly with bare areas. However, under uniform environmental conditions, non-random spatial patterns are supposed to be the long-term effects of prevailing plant-plant interactions. Therefore, competition for resources usually leads to the exclusion of some species, which causes spatial segregation, i.e. a below-average number of co-occurrences among species (Seabloom et al. 2005, Pottier et al. 2007). Conversely, the nurse-plant effect is a type of facilitative interaction in which established individuals shelter associated species from environmental extremes due to modification of the local environment (Nuñez et al. 1999, Badano et al. 2006, Dona and Galen 2007). Thus, facilitation leads to species aggregation, i.e. an above-average number of cooccurrences among species (Carlsson and Callaghan 1991, Bertness and Hacker 1994, Cavieres et al. 2006).

Because invasions of alpine grassland species into snowbeds are predicted (Grabherr 2003, Schöb et al. 2009), but the outcome of plant-plant interactions for this process is unknown, we intended to evaluate the importance of plant-plant interactions in the predicted invasions in snowbeds by means of spatial pattern analyses. In this study, we analysed small-scale spatial patterns along a snowmelt gradient in snowbeds in the Swiss Alps and hypothesised that predominant plant interactions caused non-random spatial distribution of species. The aim was to characterise the interspecific spatial relationship of plants in snowbeds with a focus on the relationship between the dominant snowbed species, subordinate snowbed species, and potentially invading alpine grassland species. The most probable underlying causes of the spatial patterns observed (environmental heterogeneity or plant interactions) were determined under consideration of three key abiotic factors (snowmelt date, soil temperature, and soil $\mathrm{pH}$ ) and plant-plant interactions. Further, the influence of the snowmelt date on the prevailing plant-plant interactions was examined.

\section{Methods}

\section{Study area}

Thirty spatially separated snowbeds in the western part of the central Alps at the Gemmi Pass, Leukerbad, Switzerland $\left(2400 \mathrm{~m}\right.$ a.s.l., $\left.46^{\circ} 25^{\prime} \mathrm{N}, 7^{\circ} 37^{\prime} \mathrm{E}\right)$ were studied. They were located within an area of approximately $0.3 \mathrm{~km}^{2}$ and had an average distance of $118 \pm 63 \mathrm{~m}(\mathrm{SD})$ between each other.

In the Gemmi Pass region, the total annual precipitation amounts to $2100 \mathrm{~mm}$, of which about two-thirds fall as snow (this and the following climatic data of the study area are from Döbeli 2000). The precipitation between July and September totals to $350 \mathrm{~mm}$ on average, mainly in the form of rain. The average annual temperature is close to $0^{\circ} \mathrm{C}$. During the growing season, from July to September, the average temperature is between $6^{\circ} \mathrm{C}$ and $9^{\circ} \mathrm{C}$. Snowbeds were located in northeast-southwestdirected hollows where the predominating northwesterly winds accumulate snow during the winter. Microtopographical patterns of periglacial hummocks, typical for arctic snowbeds, were absent in the study site (C. Schöb pers. obs.). The soil consists of deep gleyed Brown Earths or gleyed Rendzinas, developed on silic limestone bedrock (Döbeli 2000, Vonlanthen et al. 2004). The fractions of sand, silt and clay in the mineral soil particles were 51, 36 , and $13 \%$, respectively, determined by the hydrometer method (Bouyoucos 1962) modified by Day (1965). Soil 
moisture conditions are mesic with low soil suction values (Vonlanthen et al. 2006a, C. Schöb pers. obs.). Snowbeds were occasionally grazed by sheep.

Vegetation in the snowbeds studied belonged to the Salicetea herbaceae-snowbed communities (sensu Ellenberg 1996). The total vegetation cover was constant over the whole snowmelt gradient under study (Schöb et al. 2009; Fig. 1). In general, within snowbeds alpine grassland species decreased in frequency and abundance with later snowmelt, whereas subordinate snowbed species showed the opposite pattern. The three most abundant (by cover) and dominant species were Alchemilla pentaphyllea, Salix herbacea and Gnaphalium supinum (Schöb et al. 2009). The plant size of all species occurring in snowbeds was consistently low (mean canopy height approximately $5 \mathrm{~cm}$ ) and peak standing biomass was determined by Vonlanthen et al. (2006b) and averaged to $14.52 \mathrm{~g} \mathrm{~m}^{-2}$.

\section{Small-scale habitat preferences}

Because differences in small-scale habitat preferences between species may lead to non-random spatial patterns within snowbeds, we tested for differences in species distribution along three key abiotic factors for alpine plants: snowmelt date, soil $\mathrm{pH}$ and soil temperature (Kammer and Möhl 2002, Vonlanthen et al. 2006b). In 2003, weekly visits to the study site allowed localising 52 plots with four different snowmelt dates within 30 snowbeds: 2 June (snowmelt date I, 6 plots), 9 June (snowmelt date II, 20 plots), 16 June (snowmelt date III, 18 plots) and 23 June (snowmelt date IV, 8 plots). For each plot the soil $\mathrm{pH}$ of the upper $5 \mathrm{~cm}$ of mineral horizons was determined. Two soil samples were randomly collected in each plot and pooled to one composite sample per plot. Soil $\mathrm{pH}$ was measured by shaking $4 \mathrm{~g}$ of sieved soil with de-ionised water and measuring $\mathrm{pH}$ with a glass electrode in the solution extracted after $1 \mathrm{~h}$. Additionally, in 31 of the 52 plots, the soil temperature $3 \mathrm{~cm}$ below ground was measured with UTL-1 data loggers, Geotest AG. The plots with temperature measurements were haphazardly distributed over every different date of snowmelt. For analysis, the data during the vegetation period 2006 from the time of the snowmelt until 31 August were taken into account. The data loggers stored temperatures at an interval of four hours, starting at midnight. For calculations of mean maximum temperatures $\left(T_{\max }\right)$, the average of daily maxima was considered, and correspondingly, for mean minimum temperatures $\left(\mathrm{T}_{\min }\right)$, the average of daily minima. Furthermore, the average daily temperature $\left(\mathrm{T}_{\text {mean }}\right)$ was calculated.

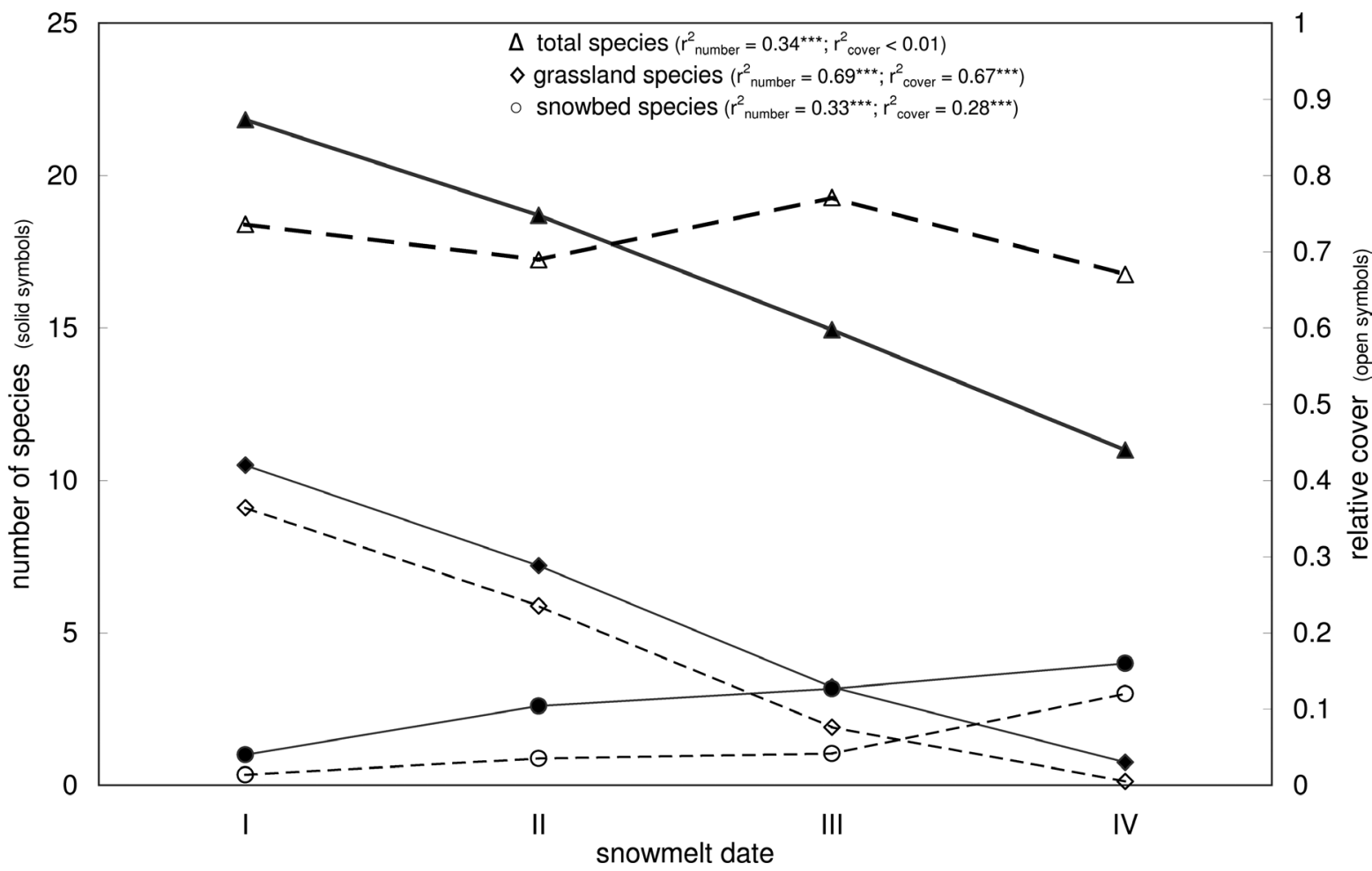

Fig. 1. Number of species (solid symbols) and relative cover (open symbols) for all species, and alpine grassland species and subordinate snowbed species separately, along the snowmelt gradient. Species groups: total species $(\Delta)$, alpine grassland species (i.e. avoiders of late-snowmelt sites; $\diamond$ ), subordinate snowbed species (i.e. snowbed specialists; $\bigcirc$ ) ${ }^{* * *}=p<0.001$. n for snowmelt date I (2 Jun 2003 ) $=6$, II (9 Jun 2003) = 20, III (16 Jun 2003) = 18, IV (23 Jun 2003) = 8. Data from Schöb et al. (2009). 
The vegetation data for the detection of differences in small-scale habitat preferences within snowbeds were sampled in a $0.16 \mathrm{~m}^{2}$ square in the centre of each plot. All vascular plant species were determined.

\section{Vegetation sampling for species spatial patterns}

In summer 2005, we selected 40 of the 52 plots with four different snowmelt dates (6 plots with snowmelt date I, 13 plots with snowmelt date II, 13 plots with snowmelt date III, 8 plots with snowmelt date IV) within 24 of the 30 snowbeds. We haphazardly placed 480 small circles with a radius of $5 \mathrm{~cm}$ among the 40 plots $(120$ circles for each snowmelt date), wherein all vascular plants were identified. The average distance between two neighbouring circle centres within a plot was $30 \mathrm{~cm}$. We chose circles with a radius of $5 \mathrm{~cm}$, because this scale may be appropriate for herbaceous communities with small-sized individuals - such as snowbeds - to detect association patterns that may primarily be interpreted as the result of neighbour interactions (Silander and Pacala 1985, van der Maarel et al. 1995, Purves and Law 2002).

In 2005, when vegetation data for species spatial patterns were sampled, the snowmelt dates were 15 days later on average compared to 2003. Nevertheless, the snowmelt regime, i.e. the chronological ranking of the plots becoming snow-free, was constant over the years. They were melting out with about the same difference in snowmelt date (seven days between two subsequent snowmelt dates) in the two years (C. Schöb pers. obs.). We assumed that the inter-annual variability in the date of snowmelt has a negligible influence on species composition in snowbeds, because the composition of predominating perennial species in snowbeds is considered conservative (Körner 2003). For convenience, the analyses of the effect of the snowmelt date on spatial patterns were referred to the original 2003 snowmelt data only.

\section{Species association analyses}

We used the following terms to describe the spatial patterns: 'co-occurrence' refers to a joint presence of two species or species groups within small circles over all plots under focus; 'aggregation' is a significantly higher co-occurrence than expected from a random distribution; conversely, 'segregation' is defined as a significantly lower co-occurrence than expected from a random distribution. In addition, we used 'association' and 'dissociation' in their usual sense, referring to the spatial distribution of two species (pair-wise spatial relationships).

We tested spatial patterns using a randomisation technique based on the variance ratio $R V=V_{\text {obs }} / V_{\text {exp }}$, where $V_{\text {obs }}$ is the observed variance of species richness in circles and
$\mathrm{V}_{\text {exp }}$ is the variance expected under the null model (Schluter 1984, Wilson 1987, Gotelli 2000). The null model assumes that plant species are randomly distributed. To generate randomised species assemblages, the presence-absence of each species was reshuffled at random, so the occurrence of one species in any of the circles did not depend on the occurrence of other species in the same circle. The number of species and the overall frequency for each species were both held to those found in the original field data (Gotelli 2000). Randomisations of co-occurrences within this constraint of fixed marginal totals randomise only the interspecific patterns; therefore, possible intraspecific aggregations will not influence the results. Each randomisation produces a new $\mathrm{V}_{\text {exp }}$ and accordingly a randomised RV. A value of $\mathrm{RV}=1$ suggests a random distribution of plants. Values of $\mathrm{RV}<1$ indicate a lower variance than expected under the null model and suggest a co-occurrence less frequently than would be expected if plants were randomly distributed, i.e. segregation. Conversely, RVs $>1$ indicate an aggregation of species. We performed 1000 randomisations and determined the significance level (one-tailed significance test) from the number of randomised RVs equal or more extreme than the RV observed (Wilson 1987).

Pair-wise associations and dissociations were tested in a similar manner using $R V=V_{\text {obs }} / V_{\text {exp }}$, where $V_{\text {obs }}$ is the observed variance in the presence and absence of the two species and $V_{\text {exp }}$ is the sum of the species variances for presence-absence under the null-model assuming that species occur independently of each other. Since pair-wise associations and dissociations cannot be tested properly for very rare species, only species with an occurrence in $\geq 5 \%$ were included.

Therefore, RV allows for testing aggregation-segregation patterns within and between species groups as well as pair-wise associations-dissociations (Kikvidze et al. 2005a).

Differences in species richness per circle in the presence versus absence of one of the dominant species were tested by independent-samples t-test. Differences in species richness in the presence of different dominant species were tested in the same way.

\section{Results}

\section{Small-scale habitat preferences of species groups}

Tests of the differences in habitat preferences between subordinate snowbed species and alpine grassland species (for definitions of these groups see the section below) revealed that snowmelt date is the predominant environmental factor controlling species distribution among snowbeds (Table 1). While alpine grassland species preferred early melting plots, the subordinate snowbed species were more 
Table 1. Small-scale habitat preferences of alpine grassland species and subordinate snowbed species within snowbeds with respect to snowmelt date, soil $\mathrm{pH}$, and soil temperature (tested with $\mathrm{T}_{\text {mean }}, \mathrm{T}_{\min }$, and $\mathrm{T}_{\max }$ ). Mean values of each environmental factor were tested for differences between species groups with independent-samples t-test. Significant p-values at $<0.05$ in bold. $\mathrm{n}$ for alpine grassland species $=13, \mathrm{n}$ for subordinate snowbed species $=8$.

\begin{tabular}{|c|c|c|c|c|c|}
\hline \multirow{2}{*}{$\begin{array}{l}\text { Environmental } \\
\text { variables }\end{array}$} & \multicolumn{2}{|c|}{ Mean \pm 1 SD } & \multicolumn{3}{|c|}{ t-test } \\
\hline & Grassland species & Snowbed species & $\mathrm{t}$ & $\mathrm{DF}$ & $\mathrm{p}$ \\
\hline Snowmelt date & 8 Jun $2003 \pm 1.8$ & 14 Jun $2003 \pm 1.5$ & -7.30 & 19 & $<0.001$ \\
\hline $\mathrm{pH}$ & $5.0 \pm 0.1$ & $5.0 \pm 0.1$ & -0.46 & 19 & 0.651 \\
\hline \multicolumn{6}{|l|}{ Temperature } \\
\hline $\mathrm{T}_{\text {mean }}$ & $9.5 \pm 0.4$ & $9.5 \pm 0.2$ & 0.45 & 19 & 0.656 \\
\hline $\mathrm{T}_{\min }$ & $5.2 \pm 0.2$ & $5.2 \pm 0.1$ & -0.03 & 19 & 0.975 \\
\hline $\mathrm{T}_{\max }$ & $16.2 \pm 0.6$ & $15.8 \pm 0.4$ & 1.57 & 19 & 0.134 \\
\hline
\end{tabular}

frequent in later melting plots. No differences were found in small-scale habitat preferences between the two opposing species groups with respect to soil $\mathrm{pH}$ and soil temperature (analysed with $\mathrm{T}_{\text {mean }}, \mathrm{T}_{\min }$, and $\mathrm{T}_{\max }$ ).

\section{Spatial patterns across the whole snowmelt gradient}

Aggregation prevailed over segregation $\left(\mathrm{RV}_{\mathrm{obs}}=1.371, \mathrm{p}\right.$ $<0.001$ ) when patterns were analysed for the entire assemblage, including all species and all snowmelt dates. However, pair-wise co-occurrences between frequent species revealed groups of spatially associated and dissociated species (Table 2). Due to the high frequency and abundance of the three dominant snowbed species Alchemilla pentaphyllea, Gnaphalium supinum, and Salix herbacea, we treated each of these species separately in subsequent analyses. The remaining frequent subordinate species could be divided into three groups according to their spatial patterns: 1) subordinate snowbed species, 2) alpine grassland species and 3) intermediary, 'indifferent' species. Subordinate snowbed species and alpine grassland species showed contrasting spatial patterns within snowbeds; while strong segregation was found between these two groups $\left(\mathrm{RV}_{\mathrm{obs}}=\right.$ $0.377, \mathrm{p}<0.001)$, within the groups the species strongly aggregated $\left(\mathrm{RV}_{\mathrm{obs}}=2.048, \mathrm{p}<0.001\right.$ and $\mathrm{RV}_{\mathrm{obs}}=3.189, \mathrm{p}$ $<0.001$ for subordinate snowbed species and alpine grassland species, respectively). The indifferent species showed associations and dissociations with either the subordinate snowbed species or the alpine grassland species (Table 2).

Overall, Alchemilla and Salix were spatially segregated from the remaining vegetation (Table 3 ), whereas Gnaphalium showed no pattern in this respect. However, spatial relationships of the three dominant species with the two contrasting species groups were different. Alchemilla significantly aggregated with the subordinate snowbed species and segregated from the alpine grassland species, contrary to Gnaphalium, which significantly aggregated with the alpine grassland species and segregated from the subordinate snowbed species. Salix segregated from the subordinate snowbed species, but showed no pattern with the alpine grassland species. Therefore, the subordinate snowbed species were more frequent in circles with Alchemilla present and less frequent in the presence of Gnaphalium and Salix (Table 4). On the contrary, alpine grassland species were more frequently found in circles with Gnaphalium present and underrepresented in those with Alchemilla present. The total species richness in circles was also dependent on the dominant species present (Table 4). In the presence of Alchemilla, species richness in circles was lower than in its absence, whereas in the presence of Gnaphalium, species richness was higher than in its absence. As a result, circles with Gnaphalium showed a significantly higher species richness than the circles with Alchemilla $(\mathrm{t}=-2.05, \mathrm{DF}=776, \mathrm{p}=0.040)$.

\section{Spatial patterns within single snowmelt dates}

Species of snowmelt dates I and IV were aggregated $\left(\mathrm{RV}_{\mathrm{obs}}\right.$ $=1.529, \mathrm{p}<0.001$ and $\mathrm{RV}_{\text {obs }}=1.328, \mathrm{p}=0.006$, respectively). For the snowmelt dates II and III, no significant aggregation or segregation was found. However, in pairwise association-dissociation-analyses for all snowmelt dates, more associations than dissociations were found between species (Fig. 2, supplementary material Appendix A1-A4). Along the snowmelt gradient the percent of significant associations-dissociations out of all possible pairwise co-occurrences decreased from the early melting plots (I: 31\%, II: 30\%) to the late melting plots (III: 18\%, IV: $19 \%)$. However, the percentage of associations decreased only to one fourth from $16 \%$ in I to $12 \%$ in IV, whereas the dissociations dropped by half from $14 \%$ in I to $7 \%$ in IV.

For single snowmelt dates, the spatial patterns of the two opponent species groups - subordinate snowbed species versus alpine grassland species - showed aggregation 


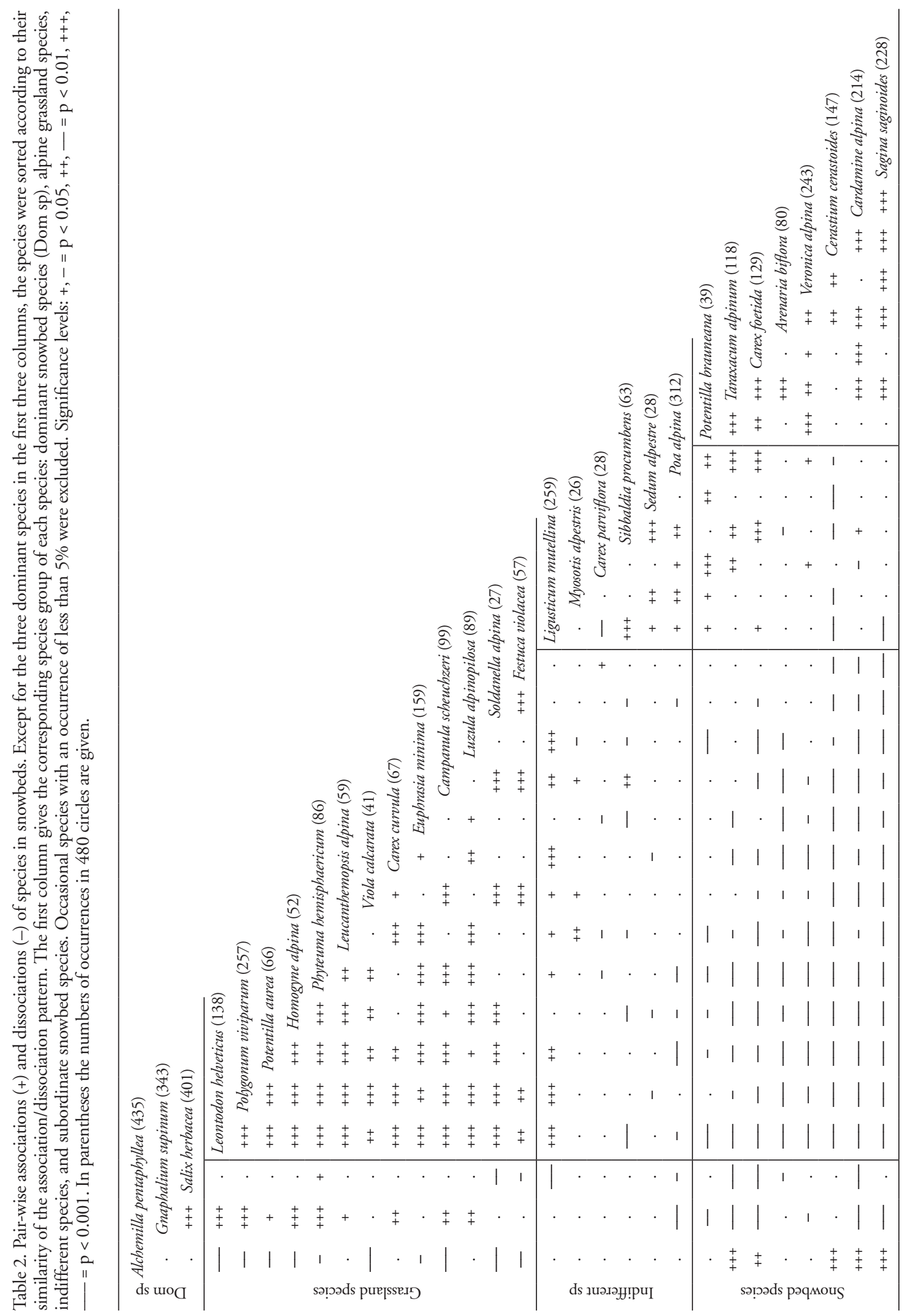


Table 3. Spatial relationships of dominant snowbed species with the remaining vegetation (All), and the two opponent groups of species (alpine grassland species and subordinate snowbed species), respectively. Spatial patterns were detected by calculating the observed variance ratio $\left(\mathrm{RV}_{\mathrm{obs}}\right)$ and comparison to the null model with randomly distributed species. A value of $\mathrm{RV}_{\mathrm{obs}}=1 \mathrm{means}$ a random distribution of species, values of $\mathrm{RV}_{\mathrm{obs}}<1$ suggest segregation, $\mathrm{RV}_{\mathrm{obs}}>1$ indicate aggregation. Significant $\mathrm{p}$-values at $<0.05$ in bold. $\mathrm{n}=480$ circles.

\begin{tabular}{|c|c|c|c|c|c|c|}
\hline \multirow{2}{*}{ Dominant species } & \multicolumn{2}{|r|}{ All } & \multicolumn{2}{|c|}{ Grassland species } & \multicolumn{2}{|c|}{ Snowbed species } \\
\hline & $\mathrm{RV}_{\mathrm{obs}}$ & $\mathrm{p}$ & $\mathrm{RV}_{\mathrm{obs}}$ & $\mathrm{p}$ & $\mathrm{RV}_{\text {obs }}$ & $\mathrm{p}$ \\
\hline Alchemilla pentaphyllea & 0.942 & $<0.001$ & 0.927 & $<0.001$ & 1.085 & $<0.001$ \\
\hline Gnaphalium supinum & 0.991 & 0.307 & 1.074 & 0.002 & 0.856 & $<0.001$ \\
\hline Salix herbacea & 0.941 & $<0.001$ & 0.993 & 0.364 & 0.921 & $<0.001$ \\
\hline
\end{tabular}

within the groups and segregation between the two groups in the earlier melting plots (Fig. 3). Toward the latest melting plots, the co-occurrences became neutral. Particularly in the early and intermediate melting plots, Alchemilla generally aggregated with subordinate snowbed species and segregated from alpine grassland species, whereas Gnaphalium and Salix showed the contrary spatial relationship (Fig. 4). Toward the latest melting plots, the co- occurrences of the dominant species with the two species groups also tended to be neutral.

The spatial relationships between the dominant species were more associative than dissociative (Table 5); Gnaphalium and Salix generally associated over the entire snowmelt gradient and Alchemilla associated with the two other dominant species only in the earliest melting plots. Dissociation was found between Alchemilla and

Table 4. Mean total number of species (A), number of alpine grassland species (B), and number of subordinate snowbed species (C) in circles $\pm 1 \mathrm{SD}$ in the presence versus absence of the dominant species over the whole snowmelt gradient and for each snowmelt date separately. Significant differences in species richness in presence versus absence of a dominant species were tested by independentsamples t-test. Significant p-values at $<0.05$ in bold. Snowmelt dates: I = 2 Jun 2003, II = 9 Jun 2003, III $=16$ Jun 2003 , IV = 23 Jun 2003. n: Alchemilla pentaphyllea (I: 96 presences/24 absences; II: 111/9; III: 116/4; IV: 112/8), Gnaphalium supinum (I: 107/13; II: 84/36; III: 75/45; IV: 77/43), Salix herbacea (I: 99/21; II: 86/34; III: 101/19; IV: 115/5).

A. Total number of species/circle

\begin{tabular}{|c|c|c|c|c|c|c|c|c|c|}
\hline \multirow[b]{2}{*}{ Date } & \multicolumn{3}{|c|}{ Alchemilla pentaphyllea } & \multicolumn{3}{|c|}{ Gnaphalium supinum } & \multicolumn{3}{|c|}{ Salix herbacea } \\
\hline & Presence & Absence & $\mathrm{p}$ & Presence & Absence & $\mathrm{p}$ & Presence & Absence & $\mathrm{p}$ \\
\hline I-IV & $9.2 \pm 2.4$ & $10.7 \pm 3.7$ & 0.012 & $9.6 \pm 2.7$ & $8.8 \pm 2.3$ & 0.001 & $9.3 \pm 2.6$ & $9.8 \pm 2.8$ & 0.085 \\
\hline I & $10.6 \pm 2.4$ & $12.8 \pm 3.3$ & 0.005 & $11.1 \pm 2.8$ & $10.4 \pm 2.4$ & 0.388 & $10.9 \pm 2.6$ & $11.3 \pm 3.3$ & 0.553 \\
\hline II & $9.7 \pm 2.4$ & $9.6 \pm 2.8$ & 0.851 & $9.9 \pm 2.3$ & $9.3 \pm 2.5$ & 0.177 & $9.9 \pm 2.2$ & $9.3 \pm 2.7$ & 0.242 \\
\hline III & $9.3 \pm 2.0$ & $8.3 \pm 1.5$ & 0.281 & $9.3 \pm 2.1$ & $9.3 \pm 1.8$ & 0.860 & $9.2 \pm 2.1$ & $9.8 \pm 1.3$ & 0.204 \\
\hline IV & $7.5 \pm 1.9$ & $7.0 \pm 2.0$ & 0.514 & $7.5 \pm 1.9$ & $7.3 \pm 1.9$ & 0.669 & $7.4 \pm 1.9$ & $7.0 \pm 1.9$ & 0.611 \\
\hline
\end{tabular}

\begin{tabular}{lrrr}
\hline \multicolumn{3}{l}{ B. Number of grassland species/circle } \\
I-IV & $2.6 \pm 2.2$ & $4.8 \pm 3.0$ & $<\mathbf{0 . 0 0 1}$ \\
I & $5.3 \pm 1.7$ & $7.1 \pm 1.6$ & $<\mathbf{0 . 0 0 1}$ \\
II & $2.5 \pm 1.5$ & $3.9 \pm 1.1$ & $\mathbf{0 . 0 1 0}$ \\
III & $1.3 \pm 1.0$ & $1.8 \pm 1.0$ & 0.410 \\
IV & $0.3 \pm 0.5$ & $0.4 \pm 0.5$ & 0.780
\end{tabular}

$\begin{array}{lll}2.8 \pm 2.5 & 1.7 \pm 2.0 & <\mathbf{0 . 0 0 1} \\ 5.6 \pm 1.9 & 6.0 \pm 1.5 & 0.503 \\ 2.9 \pm 1.4 & 2.1 \pm 1.8 & \mathbf{0 . 0 1 7} \\ 1.3 \pm 1.0 & 1.3 \pm 1.1 & 1.000 \\ 0.2 \pm 0.4 & 0.5 \pm 0.6 & \mathbf{0 . 0 4 8}\end{array}$

$\begin{array}{lll}2.5 \pm 2.4 & 2.6 \pm 2.6 & 0.610 \\ 5.6 \pm 1.9 & 6.0 \pm 1.8 & 0.376 \\ 2.9 \pm 1.4 & 1.9 \pm 1.6 & \mathbf{0 . 0 0 1} \\ 1.5 \pm 1.0 & 0.7 \pm 0.6 & <\mathbf{0 . 0 0 1} \\ 0.3 \pm 0.5 & 0.6 \pm 0.9 & 0.515\end{array}$

C. Number of snowbed species/circle

\begin{tabular}{llllllllll} 
I-IV & $2.6 \pm 1.8$ & $1.0 \pm 1.4$ & $\mathbf{< 0 . 0 0 1}$ & $2.2 \pm 1.7$ & $3.4 \pm 1.7$ & $\mathbf{< 0 . 0 0 1}$ & $2.3 \pm 1.7$ & $3.3 \pm 2.2$ & $<\mathbf{0 . 0 0 1}$ \\
I & $0.8 \pm 1.0$ & $0.2 \pm 0.5$ & $<\mathbf{0 . 0 0 1}$ & $0.7 \pm 1.0$ & $0.5 \pm 1.1$ & 0.574 & $0.7 \pm 1.0$ & $0.5 \pm 0.9$ & 0.287 \\
II & $2.7 \pm 1.7$ & $0.6 \pm 0.5$ & $<\mathbf{0 . 0 0 1}$ & $2.1 \pm 1.6$ & $3.6 \pm 1.5$ & $<\mathbf{0 . 0 0 1}$ & $2.1 \pm 1.6$ & $3.8 \pm 1.4$ & $<\mathbf{0 . 0 0 1}$ \\
III & $3.1 \pm 1.6$ & $2.0 \pm 0.8$ & 0.177 & $2.8 \pm 1.6$ & $3.5 \pm 1.6$ & $\mathbf{0 . 0 3 4}$ & $2.7 \pm 1.4$ & $5.2 \pm 1.4$ & $<\mathbf{0 . 0 0 1}$ \\
IV & $3.7 \pm 1.2$ & $3.5 \pm 0.9$ & 0.718 & $3.5 \pm 1.1$ & $3.8 \pm 1.2$ & 0.219 & $3.6 \pm 1.1$ & $4.6 \pm 0.9$ & 0.055 \\
\hline
\end{tabular}




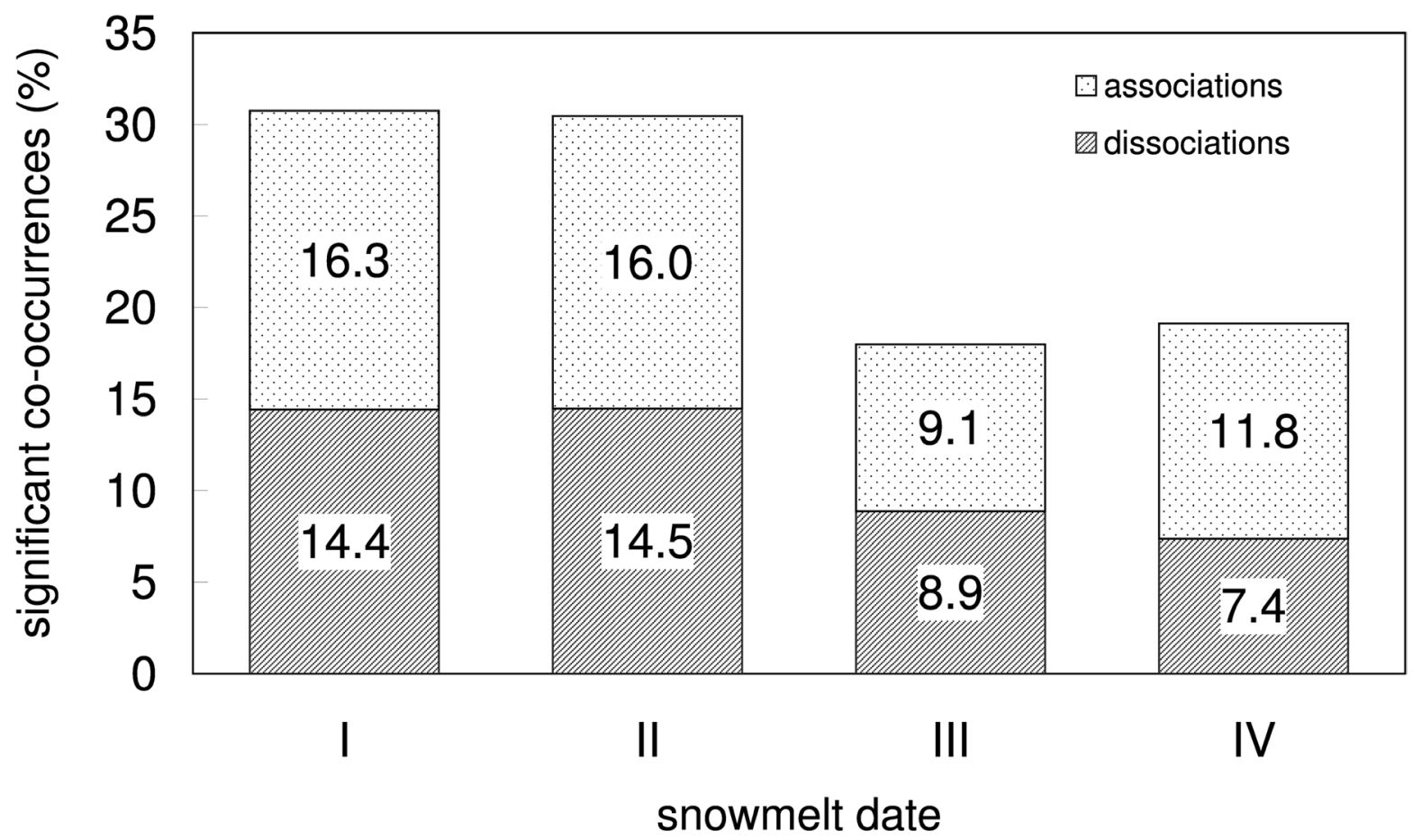

Fig. 2. Percentage of associations and dissociations out of all possible pair-wise co-occurrences for each snowmelt date. $\mathrm{n}$ for snowmelt dates I (2 Jun 2003) = 31 species, II (9 Jun 2003) = 26 species, III (16 Jun 2003) = 29 species, IV (23 Jun 2003) = 17 species. All species with an occurrence of less than $5 \%$ were excluded from pair-wise analyses.

Table 5. Spatial relationships between the dominant snowbed species for each snowmelt date. Associations and dissociations were detected by calculating the observed variance ratio $\left(\mathrm{RV}_{\mathrm{obs}}\right)$ and comparison to the null model with randomly distributed species occurrences. A value of $\mathrm{RV}_{\text {obs }}=1$ means a random distribution of species occurrences, values of $\mathrm{RV}_{\mathrm{obs}}<1$ suggest dissociation, $\mathrm{RV}_{\mathrm{obs}}>1$ indicate association. The dominant species: Alchemilla $=$ A. pentaphyllea, Gnaphalium $=$ G. supinum, and Salix $=S$. herbacea . Significance levels: ${ }^{*}(\mathrm{p}<0.05),{ }^{* *}(\mathrm{p}<0.01)$, and ${ }^{* * *}(\mathrm{p}<0.001)$. Snowmelt dates (date): I = 2 Jun 2003, II $=9$ Jun 2003, III = 16 Jun 2003, IV = 23 Jun 2003. n for each snowmelt date $=120$ circles.

\begin{tabular}{|c|c|c|c|c|c|}
\hline \multirow{3}{*}{$\frac{\text { Date }}{\mathrm{I}}$} & \multirow{3}{*}{$\begin{array}{l}\text { Species } \\
\text { Alchemilla }\end{array}$} & \multicolumn{4}{|c|}{$\mathrm{RV}_{\mathrm{obs}}$} \\
\hline & & \multicolumn{2}{|c|}{ Gnaphalium } & \multicolumn{2}{|c|}{ Salix } \\
\hline & & 1.221 & * & 1.208 & * \\
\hline & Gnaphalium & $\mathrm{x}$ & & 1.258 & $* * *$ \\
\hline \multirow[t]{2}{*}{ II } & Alchemilla & 0.839 & * & 0.905 & \\
\hline & Gnaphalium & $\mathrm{x}$ & & 1.476 & $* * *$ \\
\hline \multirow[t]{2}{*}{ III } & Alchemilla & 1.094 & & 0.936 & \\
\hline & Gnaphalium & $\mathrm{x}$ & & 1.130 & \\
\hline \multirow[t]{2}{*}{ IV } & Alchemilla & 0.894 & & 0.946 & \\
\hline & Gnaphalium & $\mathrm{x}$ & & 1.198 & $* *$ \\
\hline
\end{tabular}

Gnaphalium for snowmelt date II. The spatial patterns of the dominant species with the remaining species revealed a segregating effect of the very abundant dominant species (Table 6); Alchemilla changed from segregation to neutral co-occurrence with later snowmelt date, Gnaphalium showed the converse pattern and Salix significantly segregated in snowmelt date III.

The difference in the total species richness in the presence versus absence of different dominant species almost disappeared within single snowmelt dates (Table 4). Nevertheless, the results for the two species groups were still obvious - in the early melting plots, in the presence of Alchemilla, the richness of subordinate snowbed species was higher and the richness of alpine grassland species was lower. Conversely, particularly in the intermediate melting plots in the presence of Gnaphalium and Salix, the number of alpine grassland species was higher and the number of subordinate snowbed species lower.

\section{Discussion}

Small-scale patterns of species spatial distributions in snowbeds were strongly non-random. Our analyses revealed two ecological groups of species with different habi- 


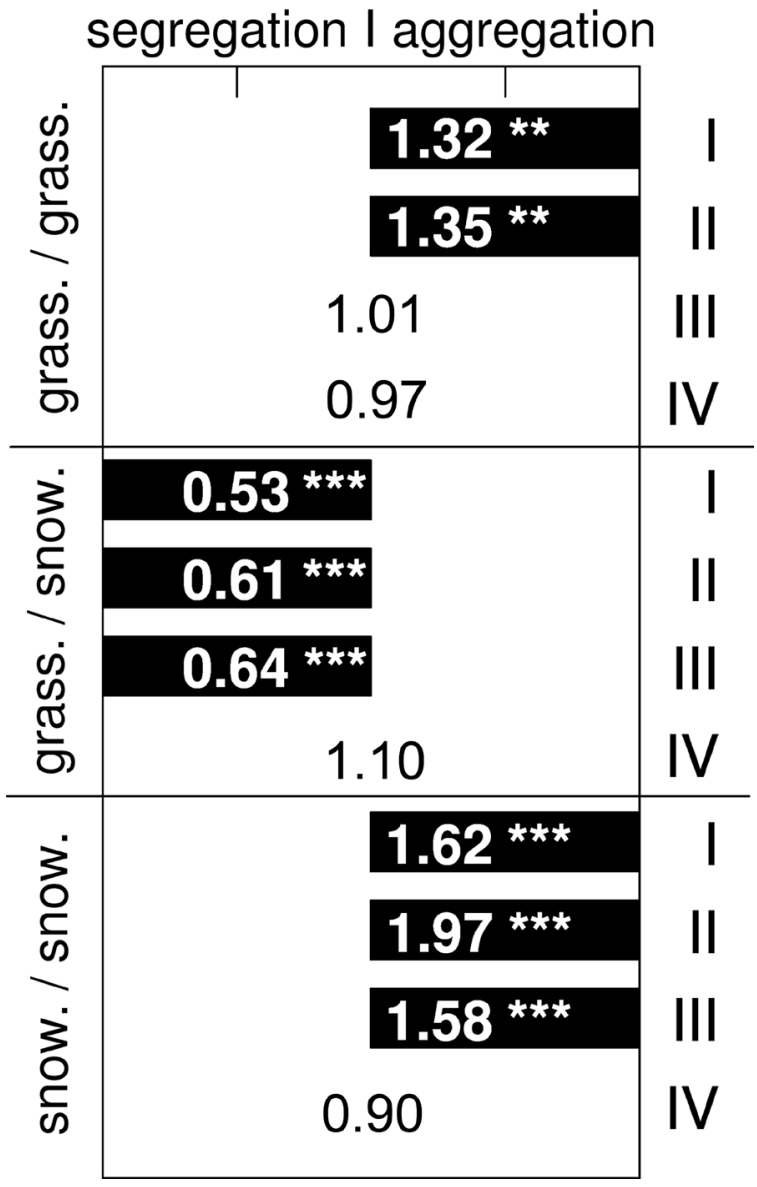

Fig. 3. Spatial relationships within and between the two opponent groups of species along the snowmelt gradient. Aggregations and segregations were detected by calculating the observed variance ratio $\left(\mathrm{RV}_{\mathrm{obs}}\right)$ and comparison to the null model with randomly distributed species. A value of $\mathrm{RV}_{\mathrm{obs}}=1$ means a random distribution of species, values of $\mathrm{RV}_{\mathrm{obs}}<1$ suggest segregation, $\mathrm{RV}_{\mathrm{obs}}>1$ indicate aggregation. Species groups: alpine grassland species (grass.; snowmelt date I: 13 species, II: 11, III: 9, IV: 2) and subordinate snowbed species (snow.; I: 5, II: 7, III + IV: 8). Significant $\mathrm{RV}_{\text {obs }}$-values displayed in filled columns are marked with ${ }^{*}(\mathrm{p}<0.05),{ }^{* *}(\mathrm{p}<0.01),{ }^{* * *}(\mathrm{p}<0.001)$. Snowmelt dates: I = 2 Jun 2003, II = 9 Jun 2003, III = 16 Jun 2003, IV = 23 Jun 2003. $\mathrm{n}$ for each snowmelt date $=120$ circles.

tat preferences within snowbeds - alpine grassland species with higher frequency in the early melting plots and subordinate snowbed species, which were more frequent in the late melting plots. Consequently, the observed spatial patterns in snowbeds are the result of environmental heterogeneity and plant-plant interactions, particularly depending on the scale considered. The analyses of the small-scale habitat preferences of the species in snowbeds revealed a high influence of the snowmelt gradient on the species distribution in snowbeds (Tomaselli 1991, Razzhivin 1994, Schöb et al. 2009). Since alpine grassland species and sub- ordinate snowbed species colonise similar microsites with regard to soil temperature and soil $\mathrm{pH}$, we assume these two abiotic factors cannot be responsible for non-random spatial patterns between these groups. Therefore, spatial patterns on the scale of the whole snowmelt gradient may particularly reflect environmental heterogeneity caused by the snowmelt gradient, but spatial patterns within individual snowmelt dates must mainly be the result of plantplant interactions, although some hidden environmental micro-heterogeneities may also play a role.

\section{Spatial patterns and environmental heterogeneity}

Due to different habitat preferences of groups of species along the snowmelt gradient in snowbeds, within-group aggregation was most obvious at the first and the latest snowmelt date, where either alpine grassland species or subordinate snowbed species were most abundant, respectively. The contrasting distributional patterns of these two ecological groups of species are in line with the division of vascular plant species in snowbeds into different categories based on their behaviour along a snowmelt gradient, which we performed in an earlier study (Schöb et al. 2009). The alpine grassland species correspond to the category of the 'avoiders of late-snowmelt sites' with a significantly decreasing frequency of occurrence along the snowmelt gradient. Accordingly, the subordinate snowbed species correspond to the 'snowbed specialists' with an increasing frequency of occurrence with a later snowmelt date.

\section{Spatial patterns and plant-plant interactions}

Along the snowmelt gradient, a clear decrease in the number of associations and dissociations out of all pair-wise co-occurrences could be detected. It seems that neighbour effects in general became less important with later snowmelt date in snowbeds. Selective forces related to survival and tolerance of late snowmelt conditions are likely to be relatively more important and intense than those related to competitive strength at the harsher end of the gradient (Brooker and Callaghan 1998). This is in accordance with the C-S-R model of Grime (2001) and applies for a decrease in dissociations between species. On the other hand, a decrease in associations may indicate less important facilitation, which is an unusual finding for harsh environments (Bertness and Callaway 1994, Brooker and Callaghan 1998, Choler et al. 2001, Kikvidze et al. 2005b). However, the key environmental factor in snowbeds, the snowmelt date, seems difficult to ameliorate in contrast with other environmental stress factors such as excessive light or wind (Callaway 2007, Brooker et al. 2008). Most of the abiotic factors characterising snowbeds at our study site (Vonlanthen et al. 2006a) need not to be, or can hardly 
Alchemilla pentaphyllea

segregation I aggregation

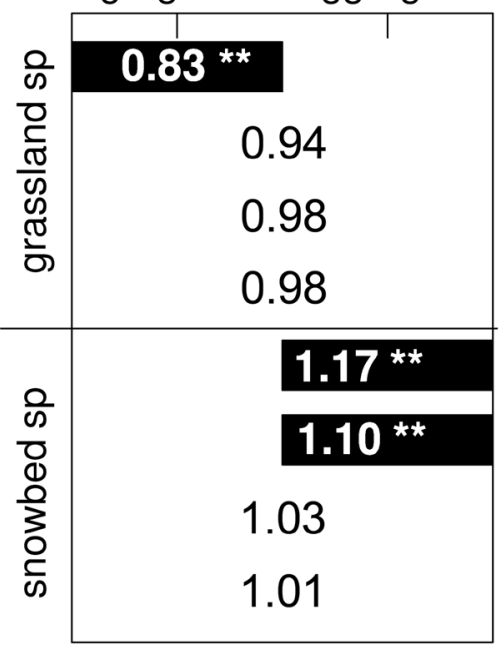

Gnaphalium supinum
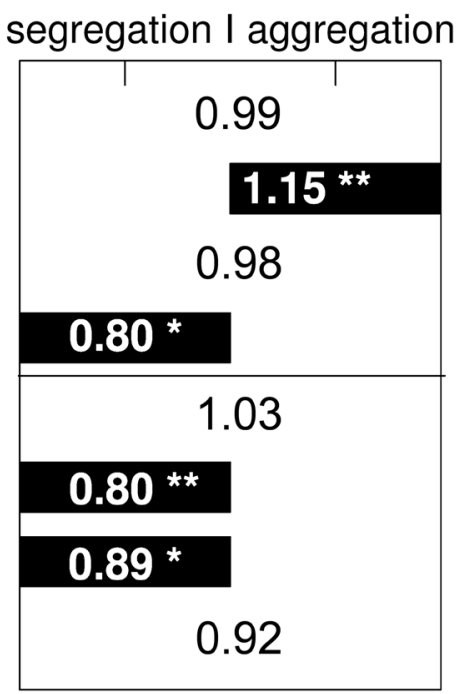

Salix herbacea

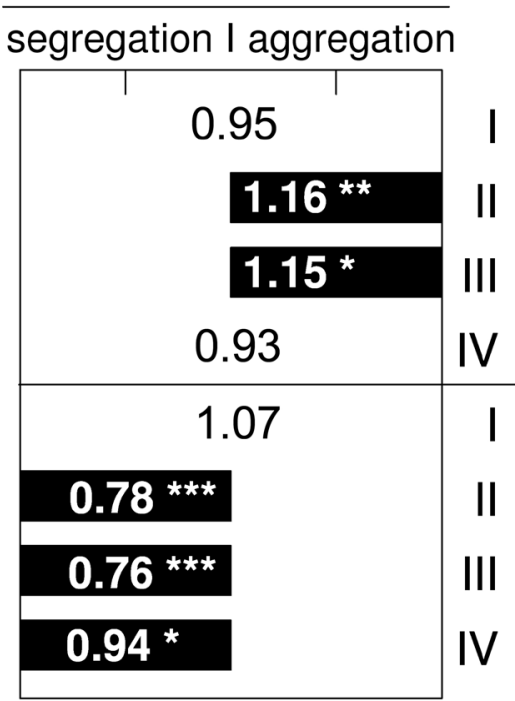

Fig. 4. Spatial relationships of dominant snowbed species with two contrasting species groups along the snowmelt gradient. Aggregations and segregations were detected by calculating the observed variance ratio $\left(\mathrm{RV}_{\mathrm{obs}}\right)$ and comparison to the null model with randomly distributed species. A value of $\mathrm{RV}_{\mathrm{obs}}=1$ means a random distribution of species, values of $\mathrm{RV}_{\mathrm{obs}}<1$ suggest segregation, $R V_{\mathrm{obs}}>1$ indicate aggregation. The three dominant species are Alchemilla pentaphyllea (I: 96 occurrences, II: 111, III: 116, IV: 112), Gnaphalium supinum (I: 107, II: 84, III: 75, IV: 77), and Salix herbacea (I: 99, II: 86, III: 101, IV: 115). Species groups: alpine grassland species

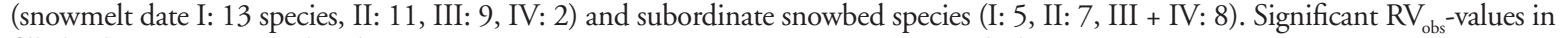
filled columns are marked with ${ }^{*}(\mathrm{p}<0.05),{ }^{* *}(\mathrm{p}<0.01),{ }^{* * *}(\mathrm{p}<0.001)$. Snowmelt dates: I = 2 Jun 2003 , II $=9$ Jun 2003 , III $=16$ Jun 2003, IV = 23 Jun 2003. $\mathrm{n}$ for each snowmelt date $=120$ circles.

be ameliorated, although low temperatures and high radiation may be alleviated by benefactor plants to some extent. This may be important for recruitment and development of plants after snowmelt. However, under extreme stress, such habitat amelioration by a benefactor species may not be enough for a beneficiary species to survive (Michalet et al. 2006). An additional factor reducing facilitative as well as competitive interactions in later melting sites may be the generally smaller plant size of species compared to those species colonising early melting sites (Tomaselli 1991).

Nevertheless, the general trend of decreasing dissociations with later snowmelt date and particularly the sharp decrease in dissociations compared to associations support the predictions of the stress-gradient hypothesis (Bertness and Callaway 1994). Such shifts in the small-scale spatial arrangement of species along gradients toward environmental severity have been documented in several alpine systems (Choler et al. 2001, Kikvidze et al. 2005b, Dullinger et al. 2007) and also are now confirmed on a small scale by our study in snowbed communities. The fact that dissociations co-occurred with associations even in the latest melting plots can be explained by the balance of competition and facilitation which shifted along the snowmelt gradient, as suggested by a conceptual model by Holmgren et al. (1997, see also Pugnaire and Luque 2001, Michalet et al. 2006). However, our findings of an increasing impor-

Table 6. Spatial relationships of dominant snowbed species with the remaining vegetation for each snowmelt date. Aggregations and segregations were detected by calculating the observed variance ratio $\left(\mathrm{RV}_{\mathrm{obs}}\right)$ and comparison to the null model with randomly distributed species. A value of $\mathrm{RV}_{\mathrm{obs}}=1$ means a random distribution of species, values of $\mathrm{RV}_{\mathrm{obs}}<1$ suggest segregation, $R V_{\mathrm{obs}}>1$ indicate aggregation. Significant p-values at $<0.05$ in bold. Snowmelt dates: I = 2 Jun 2003, II = 9 Jun 2003, III = 16 Jun 2003 , IV = 23 Jun 2003. $\mathrm{n}$ for each snowmelt date $=120$ circles .

\begin{tabular}{|c|c|c|c|c|c|c|c|c|}
\hline \multirow{2}{*}{ Dominant species } & \multicolumn{2}{|c|}{ I } & \multicolumn{2}{|c|}{ II } & \multicolumn{2}{|c|}{ III } & \multicolumn{2}{|c|}{ IV } \\
\hline & $\mathrm{RV}_{\mathrm{obs}}$ & $\mathrm{p}$ & $\mathrm{RV}_{\text {obs }}$ & $\mathrm{p}$ & $\mathrm{RV}_{\mathrm{obs}}$ & $\mathrm{p}$ & $\mathrm{RV}_{\mathrm{obs}}$ & $\mathrm{p}$ \\
\hline Alchemilla pentaphyllea & 0.881 & 0.001 & 0.980 & 0.195 & 1.002 & 0.450 & 0.981 & 0.255 \\
\hline Gnaphalium supinum & 0.992 & 0.375 & 0.974 & 0.257 & 0.900 & 0.009 & 0.902 & 0.034 \\
\hline Salix herbacea & 0.949 & 0.050 & 0.970 & 0.206 & 0.900 & 0.001 & 0.988 & 0.257 \\
\hline
\end{tabular}


tance of facilitation compared to competition in late melting plots is in contrast to other studies in the alpine zone which showed that facilitation increased with decreasing snow-melting dates (Choler et al. 2001, Michalet et al. 2002). This discrepancy in the results may be explained by an inherent difference of non-random spatial patterns versus performance measures after neighbour removal; they reflect different stages of the effect of plant interactions on neighbours (Silvertown et al. 1994). Whereas spatial patterns reflect the long-term outcome of plant interactions, performance measures are a sign of short-term effects of interacting plants. Further, spatial patterns reflect the importance of competition, whereas Choler et al. (2001) measured intensity of competition with competition indices, and these different measures of competition are linked to each other but need not to be tightly correlated (Welden and Slauson 1986).

On the level of species groups, the spatial segregation between alpine grassland species and subordinate snowbed species found in our study was probably due to competitive interactions among plants, which was especially important at early melting sites. The competitively superior alpine grassland species, together with the dominant species Gnaphalium and Salix, could exclude the competitively inferior subordinate snowbed species, particularly from the earlier melting plots. Another dominant species, $\mathrm{Al}$ chemilla, seems to be competitively inferior like the subordinate snowbed species, but might profit from facilitation with Gnaphalium and Salix in the earliest melting plots. In the later melting plots the clear hierarchy in competitive strength for the species groups and the dominant species disappeared. This may be due to the very short growing season in the latest melting plots. For these sites we suppose that the competitive ability of subordinate snowbed species outdoes that of the intrinsically more competitive alpine grassland species, because the latter were at the very end of their physiological tolerances. Such differences of competitive hierarchies between species in different environments are also known from other studies (Rice and Menke 1985, Rejmánek and Lepš 1996, Michalet et al. 2006). Therefore, we assume that the inability to cope with the severe environmental conditions prevailing in late melting snowbeds currently restrict the alpine grassland species to the earlier melting sites (Körner 2003, Choler 2005). Conversely, the subordinate snowbed species seem to be pushed back to the later melting sites due to competitive exclusion by alpine grassland species under the milder growing conditions in early melting sites (Heegaard and Vandvik 2004).

We acknowledge that it is not possible to definitively prove that the observed spatial patterns were generated by plant-plant interactions based on the examination of spatial patterns alone (Schluter 1984, McCulloch 1985, Rejmánek and Lepš 1996). However, the interpretation of aggregation and segregation being primarily the consequence of biotic interactions relative to the impact of all other environmental factors (competition-facilitation importance sensu Brooker et al. 2005, see also Brooker and Kikvidze 2008) is a reasonable and commonly used way of thinking at the scale used in our study (Silander and Pacala 1985, Seabloom et al. 2005, le Roux and McGeoch 2008, Reitalu et al. 2008). However, Choler et al. (2001) showed in a neighbour-removal experiment that in alpine environments, competition (measured with competition intensity indices) was not as tightly related to spatial dissociation as was facilitation related to association of species. But, as mentioned above, these measures need not necessarily be tightly positively correlated, since they measure two different aspects of competition: the importance and the intensity (Welden and Slauson 1986, Brooker et al. 2005, Brooker and Kikvidze 2008). Further, they reflect different stages of the effect of interactions on neighbouring plants (Silvertown et al. 1994). Spatial patterns reflect the result of decades of interacting plants on the population whereas neighbour removal experiments reveal the short-term effects of neighbouring species on species performance. Therefore, competition between two species may reduce performance of the inferior plant species. This may lead to continuous spatial segregation of these species. After segregation took place, segregation was still observable but the effect of the competitor species on the performance of the inferior species will most probably be reduced or negligible. However, even if these measures are not tightly correlated, the reduced performance of the inferior plant species as well as the spatial segregation of the two species resulted from plant-plant interactions, i.e. competition.

\section{Spatial patterns and hidden environmental heterogeneity}

Microtopographical changes resulting from periglacial processes are frequent in snowbed areas (Tomaselli 1991). Contrasting spatial patterns of dominant snowbed species have been related to such microtopographical variations, such as small convexities (Tomaselli 1991, Choler 2005). Tomaselli (1991) showed that habitats dominated by Gnaphalium and Salix were not waterlogged and were generally more disturbed. Many subordinate snowbed species are excluded from these microhabitats and are found in less disturbed patches together with Alchemilla. Our results are in line with these reports although no obvious microscale landforms such as hummocks were noticeable at our site. Whereas Alchemilla aggregated with subordinate snowbed species, the other two dominant species Gnaphalium and Salix aggregated with each other and with the alpine grassland species. Therefore, the conditions prevailing in the microhabitats dominated by Gnaphalium or Salix, which regularly aggregate with alpine grassland species, seem to be closer to those in mesic alpine grasslands compared to the microhabitats colonised by Alchemilla. Consequently, patches with Alchemilla showed a somewhat different spe- 
cies composition compared to patches with Gnaphalium or Salix. Therefore, in addition to neighbour effects, we suggest that there are some hidden small-scale environmental heterogeneities causing non-random spatial patterns in snowbeds.

\section{Snowbeds in a changing climate}

The earlier snowmelt in spring due to climate change will cause an increase in the number of species in snowbeds (Schöb et al. in press). The species invading snowbeds will particularly be typical and common alpine grassland species. This prediction can be supported by the fact that under ameliorated growing conditions selective forces will focus more on competitors than on stress-tolerators (Grime 2001) and by observations of Grabherr (2003), who found Carex curvula and Nardus stricta to invade snowbeds. Pursuant to our study, the invasion of alpine grassland species in snowbeds will most probably take place through patches in snowbeds dominated by Gnaphalium or Salix. These microhabitats seem to be more prone to the establishment of grassland species and may function as a source habitat of invading alpine grassland species for further spreading in snowbeds. Alpine grassland species therefrom can reach a higher abundance in snowbeds, further enhancing their competitive pressure on the remaining species. This will lead to a gradual replacement of the subordinate snowbed species by more competitive grassland species, even in the later melting sites. Therefore, subordinate snowbed species may be highly endangered due to the loss of their habitat where they are the most competitive.

We did not find any evidence that plant-plant interactions in snowbeds would be able to overturn the invasion of alpine grassland species due to predicted climate change (but see Suttle et al. 2007 and their research from a Californian grassland). Rather, our results suggest that the replacement of subordinate snowbed species by alpine grassland species will be accelerated by an increasing importance of competition with earlier snowmelt due to climate change and the accompanied invasion of alpine grassland species. This is in line with other studies which have shown an increasing importance of competitive interactions with climate change (Klanderud 2005, Klanderud and Totland 2007, but see Wipf et al. 2006 for early flowering tundra species). Additionally, the availability of susceptible microhabitats over the whole snowmelt gradient will facilitate the invasion of alpine grassland species. Facilitation of invaders would further accelerate the invasion and replacement processes (Badano et al. 2007, Bulleri et al. 2008).

The present study shows that climate warming will most probably have profound effects on a typical alpine plant community, not only through changed climatic conditions but also through changes in biotic interactions. As a consequence, a species loss, particularly of highly spe- cialised subordinate snowbed species, must be assumed. Even if the plant species richness in snowbeds ( $\alpha$-diversity) may increase by invasions of alpine grassland species due to climate change, the regional diversity ( $\gamma$-diversity) may decrease through the extinction of subordinate snowbed species. Therefore, this study demonstrates the high sensitivity of alpine vegetation to climate change and highlights the importance of plant-plant interactions and the availability of microhabitats prone to invasion for vegetation dynamics. Further studies on the mechanisms of species replacement due to earlier melt-out of snowbeds must focus on plant interactions and microhabitat formation.

Acknowledgements - The study was financially supported by the 'Stiftung zur Förderung der wissenschaftlichen Forschung' of the Univ. of Bern and the Centre of Research and Development of PHBern. We thank the Inst. S1 of PHBern for infrastructural support and W. and S. Loretan for accommodation at the Berghotel Wildstrubel. ZK is grateful to the Spanish Ministry of Education and Science grant CGL2004-03604-C02-01.

\section{References}

Badano, E. I. et al. 2005. Slope aspect influences plant association patterns in the Mediterranean matorral of central Chile. - J. Arid Environ. 62: 93-108.

Badano, E. I. et al. 2006. Assessing impacts of ecosystem engineers on community organization: a general approach illustrated by effects of a high-Andean cushion plant. - Oikos 115: 369-385.

Badano, E. I. et al. 2007. Ecosystem engineering facilitates invasions by exotic plants in high-Andean ecosystems. - J. Ecol. 95: 682-688.

Beniston, M. et al. 2003. Estimates of snow accumulation and volume in the Swiss Alps under changing climatic conditions. - Theor. Appl. Climatol. 76: 125-140.

Bertness, M. D. and Callaway, R. 1994. Positive interactions in communities. - Trends Ecol. Evol. 9: 191-193.

Bertness, M. D. and Hacker, S. D. 1994. Physical stress and positive associations among marsh plants. - Am. Nat. 144: 363-372.

Billings, W. D. and Bliss, L. C. 1959. An alpine snowbank environment and its effects on vegetation, plant development, and productivity. - Ecology 40: 388-397.

Björk, R. G. and Molau, U. 2007. Ecology of alpine snowbeds and the impact of global change. - Arct. Antarct. Alp. Res. 39: 34-43.

Bouyoucos, G. J. 1962. Hydrometer method improved for making particle size analyses of soils. - Agron. J. 54: 464-465.

Brooker, R. W. and Callaghan, T. V. 1998. The balance between positive and negative plant interactions and its relationship to environmental gradients: a model. - Oikos 81: 196-207.

Brooker, R. et al. 2005. The importance of importance. - Oikos 109: 63-70.

Brooker, R. W. and Kikvidze, Z. 2008. Importance: an overlooked concept in plant interaction research. - J. Ecol. 96: 703-708.

Brooker, R. W. et al. 2008. Facilitation in plant communities: the past, the present, and the future. - J. Ecol. 96: 18-34. 
Bulleri, F. et al. 2008. Beyond competition: incorporating positive interactions between species to predict ecosystem invasibility. - PloS Biol. 6: e162. doi: 10.1371/journal.pbio.0060162.

Callaway, R. M. 2007. Positive interactions and interdependence in plant communities. - Springer.

Cannone, N. et al. 2007. Unexpected impacts of climate change on alpine vegetation. - Front. Ecol. Environ. 5: 360-364.

Carlsson, B. A.. and Callaghan, T. V. 1991. Positive plant interactions in tundra vegetation and the importance of shelter. $-\mathrm{J}$. Ecol. 79: 973-983.

Cavieres, L. A. et al. 2006. Positive interactions between alpine plant species and the nurse cushion plant Laretia acaulis do not increase with elevation in the Andes of central Chile. New Phytol 169: 59-69.

Choler, P. 2005. Consistent shifts in alpine plant traits along a mesotopographical gradient. - Arct. Antarct. Alp. Res. 37: 444-453.

Choler, P. et al. 2001. Facilitation and competition on gradients in alpine plant communities. - Ecology 82: 3295-3308.

Day, P. 1965. Particle fractionation and particle size analysis. In: Black, C. A. (ed.), Methods of soil analysis. Am. Soc. Agr., pp. 545-567.

Döbeli, C. 2000. Das hochalpine Geoökosystem der Gemmi (Walliser Alpen): eine landschaftsökologische Charakterisierung und der Vergleich mit der arktischen Landschaft (Liefdefjorden, Nordwest-Spitzbergen). - Physio-geographica 28: 1-193.

Dona, A. J. and Galen, C. 2007. Nurse effects of alpine willows (Salix) enhance over-winter survival at the upper range limit of fireweed, Chamerion angustifolium. - Arct. Antarct. Alp. Res. 39: 57-64.

Dullinger, S. et al. 2007. Weak and variable relationships between environmental severity and small-scale co-occurrence in alpine plant communities. - J. Ecol. 95: 1284-1295.

Ellenberg, H. 1996. Vegetation Mitteleuropas mit den Alpen. UTB Eugen Ulmer.

Gotelli, N. J. 2000. Null model analysis of species co-occurrence patterns. - Ecology 81: 2606-2621.

Grabherr, G. 2003. Alpine vegetation dynamics and climate change - a synthesis of long-term studies and observations. - In: Nagy, L. et al. (eds), Alpine biodiversity in Europe. Springer, pp. 399-409.

Grime, J. P. 2001. Plant strategies, vegetation processes, and ecosystem properties. (2nd ed.). - Wiley.

Guisan, A. and Theurillat, J.-P. 2000. Assessing alpine plant vulnerability to climate change: a modelling perspective. - Integr. Assess. 1: 307-320.

Heegaard, E. and Vandvik, V. 2004. Climate change affects the outcome of competitive interactions - an application of principle response curves. - Oecologia 139: 459-466.

Holmgren, M. et al. 1997. The interplay of facilitation and competition in plant communities. - Ecology 78: 1966-1975.

Kammer, P. M. and Möhl, A. 2002. Factors controlling species richness in alpine plant communities: an assessment of the importance of stress and disturbance. - Arct. Antarct. Alp. Res. 34: 398-407.

Keller, F. et al. 2000. Evidence of response of vegetation to environmental change on high-elevation sites in the Swiss Alps. - Reg. Environ. Change 1: 70-77.

Kikvidze, Z. et al. 2005a. Small-scale guild proportions and niche complementarity in a Caucasian subalpine hay meadow. - J. Veg. Sci. 16: 565-570.
Kikvidze, Z. et al. 2005b. Linking patterns and processes in alpine plant communities: a global study. - Ecology 86: 1395-1400.

Klanderud, K. 2005. Climate change effects on species interactions in an alpine plant community. - J. Ecol. 93: 127-137.

Klanderud, K. and Totland, Ø. 2007. The relative role of dispersal and local interactions for alpine plant community diversity under simulated climate warming. - Oikos 116: 1279-1288.

Körner, C. 2003. Alpine plant life: functional plant ecology of high mountain ecosystems. - Springer.

Kullman, L. 2002. Rapid recent range-margin rise of tree and shrub species in the Swedish Scandes. - J. Ecol. 90: 68-77.

le Roux, P. C. and McGeoch, M. A. 2008. Spatial variation in plant interactions across a severity gradient in the sub-Antarctic. - Oecologia 155: 831-844.

McCulloch, C. E. 1985. Variance tests for species associations. Ecology 66: 1676-1681.

Michalet, R. et al. 2002. Plant community composition and biomass on calcareous and siliceous substrates in the northern French Alps: comparative effects of soil chemistry and water status. - Arct. Antarct. Alp. Res. 34: 102-113.

Michalet, R. et al. 2006. Do biotic interactions shape both sides of the humped-back model of species richness in plant communities? - Ecol. Lett. 9: 767-773.

Nuñez, C. I. et al. 1999. Species associations and nurse plant effects in patches of high-Andean vegetation. - J. Veg. Sci. 10: 357-364.

Pottier, J. et al. 2007. Integrating ecological features of species in spatial pattern analysis of a plant community. - J. Veg. Sci. 18: 223-230.

Pugnaire, F. I. and Luque, M. T. 2001. Changes in plant interactions along a gradient of environmental stress. - Oikos 93: 42-49.

Purves, D. W. and Law, R. 2002. Fine-scale spatial structure in a grassland community: quantifying the plant's-eye view. - J. Ecol. 90: 121-129.

Razzhivin, V. Y. 1994. Snowbed vegetation of far northeastern Asia. - J. Veg. Sci. 5: 829-842.

Reitalu, T. et al. 2008. Plant species segregation on different spatial scales in semi-natural grasslands. - J. Veg. Sci. 19: 407-416.

Rejmánek, M. and Lepšs, J. 1996. Negative associations can reveal interspecific competition and reversal of competitive hierarchies during succession. - Oikos 76: 161-168.

Rice, K. J. and Menke, J. W. 1985. Competitive reversals and environment-dependent resource partitioning in Erodium. Oecologia 67: 430-434.

Schluter, D. 1984. A variance test for detecting species associations, with some example applications. - Ecology 65: 9981005.

Schöb, C. et al. 2009. Small scale vascular plant species distribution in snowbeds and its sensitivity to climate change. Plant Ecol. 200: 91-104.

Seabloom, E. W. et al. 2005. Spatial signature of environmental heterogeneity, dispersal, and competition in successional grasslands. - Ecol. Monogr. 75: 199-214.

Silander Jr., J. A. and Pacala, S. W. 1985. Neighborhood predictors of plant performance. - Oecologia 66: 256-263.

Silvertown, J. et al. 1994. Spatial competition between grasses - rates of mutual invasion between four species and the interaction with grazing. - J. Ecol. 82: 31-38. 
Suttle, K. B. et al. 2007. Species interactions reverse grassland responses to changing climate. - Science 315: 640-642.

Theurillat, J.-P. and Guisan, A. 2001. Potential impact of climate change on vegetation in the European Alps: a review. - Clim. Change 50: 77-109.

Thiéry, J. M. et al. 1995. A model simulating the genesis of banded vegetation patterns in Niger. - J. Ecol. 83: 497-507.

Thuiller, W. et al. 2005. Climate change threats to plant diversity in Europe. - Proc. Natl Acad. Sci. USA 102: 8245-8250.

Tomaselli, M. 1991. The snow-bed vegetation in the northern Apennines. - Vegetatio 94: 177-189.

van der Maarel, E. et al. 1995. Variation in species richness on small grassland quadrats: niche structure or small-scale plant mobility? - J. Veg. Sci. 6: 741-752.

Vonlanthen, C. M. et al. 2004. Charakterisierung ökologischer Standortfaktoren in alpinen Pflanzengemeinschaften. - Mitt. Naturforschenden Gesellschaft Bern 61: 49-77.
Vonlanthen, C. M. et al. 2006a. Alpine plant communities: a statistical assessment of their relation to microclimatological, pedological, geomorphological, and other factors. - Phys. Geogr. 27: 137-154.

Vonlanthen, C. M. et al. 2006b. Alpine vascular plant species richness: the importance of daily maximum temperature and pH. - Plant Ecol. 184: 13-25.

Welden, C. W. and Slauson, W. L. 1986. The intensity of competition versus its importance: an overlooked distinction and some implications. - Q. Rev. Biol. 61: 23-44.

Wilson, J. B. 1987. Methods for detecting non-randomness in species co-occurrences: a contribution. - Oecologia 73: 579-582.

Wipf, S. et al. 2006. Advanced snowmelt causes shift towards positive neighbour interactions in a subarctic tundra community. - Glob. Change Biol. 12: 1496-1506. 


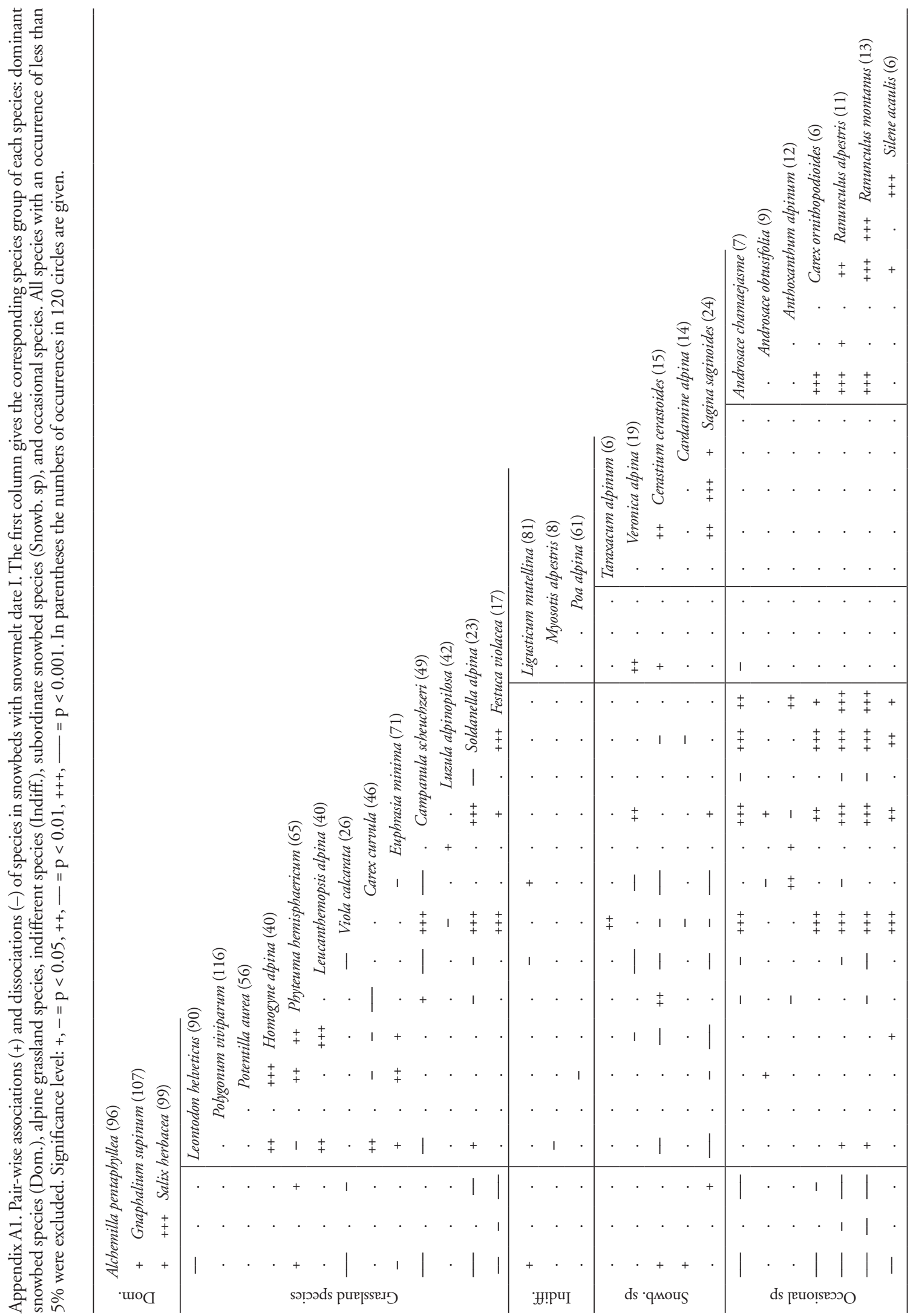




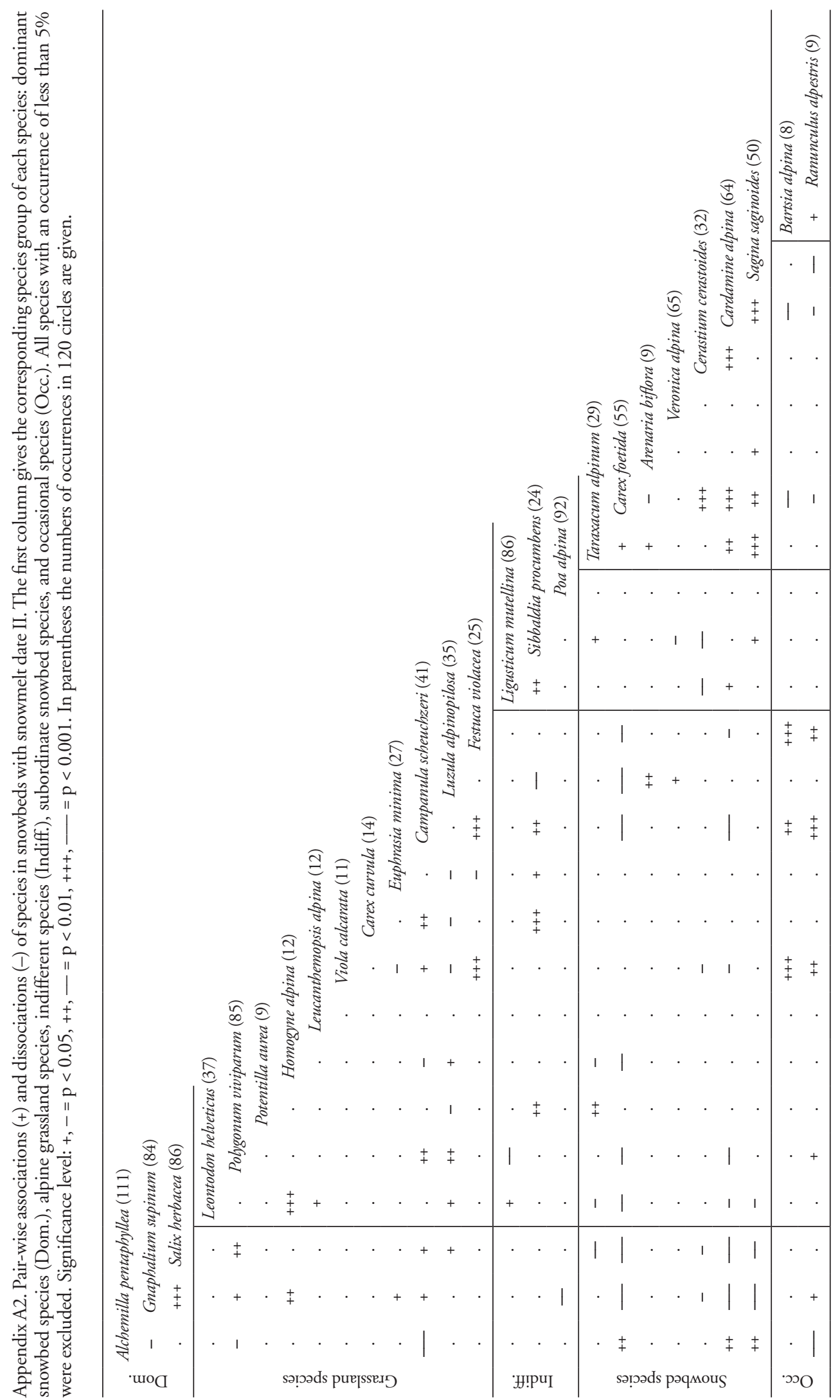




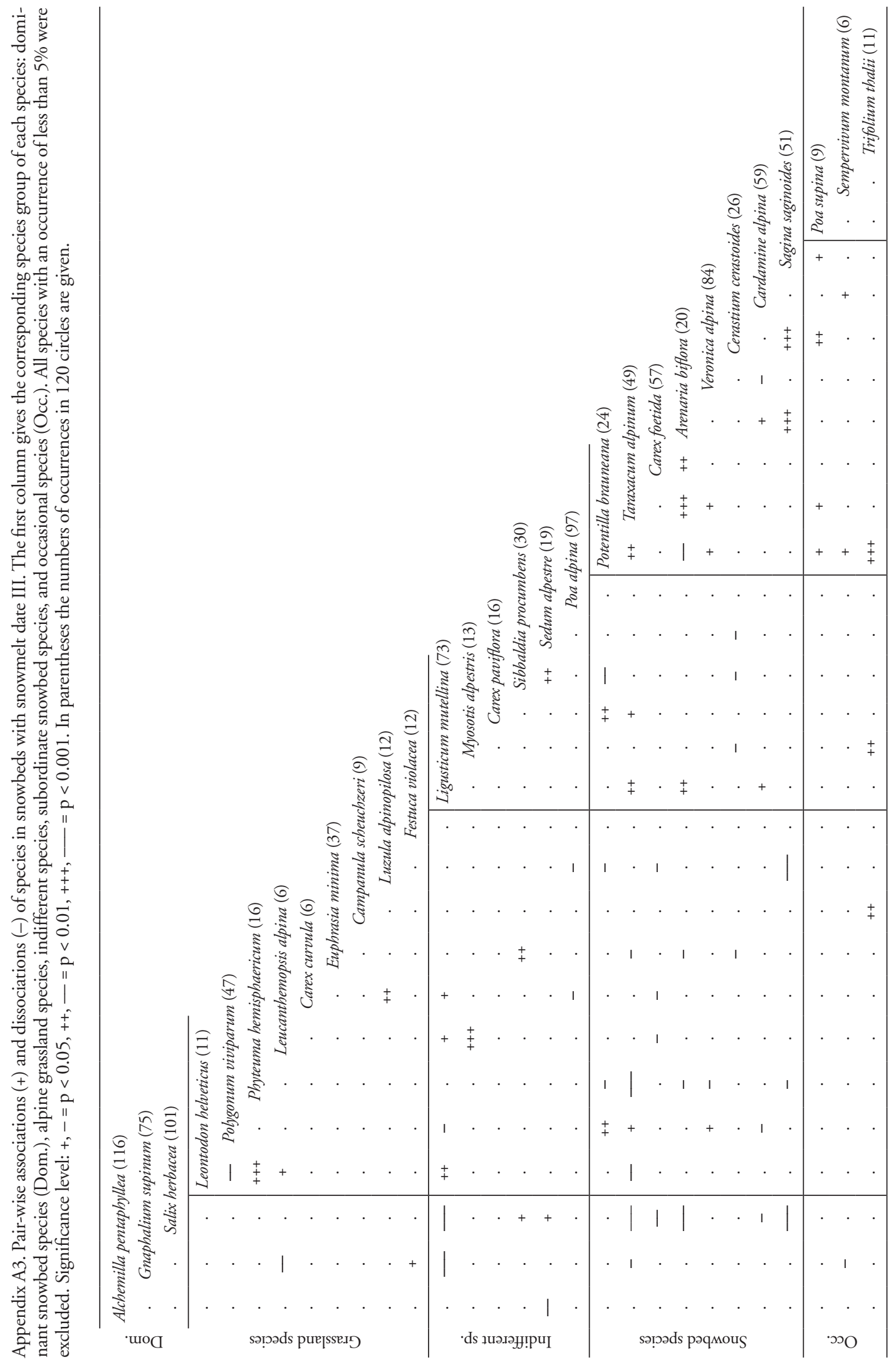


Appendix A4. Pair-wise associations (+) and dissociations (-) of species in snowbeds with snowmelt date IV. The first column gives the corresponding species group of each species: dominant snowbed species (Dom.), alpine grassland species (Gr. sp), indifferent species (Indiff.), subordinate snowbed species, and occasional species (Occ.). All species with an occurrence of less than 5\% were excluded. Significance level: $+,-=p<0.05,++,-=p<0.01,+++,-=p<0.001$. In parentheses the numbers of occurrences in 120 circles are given.

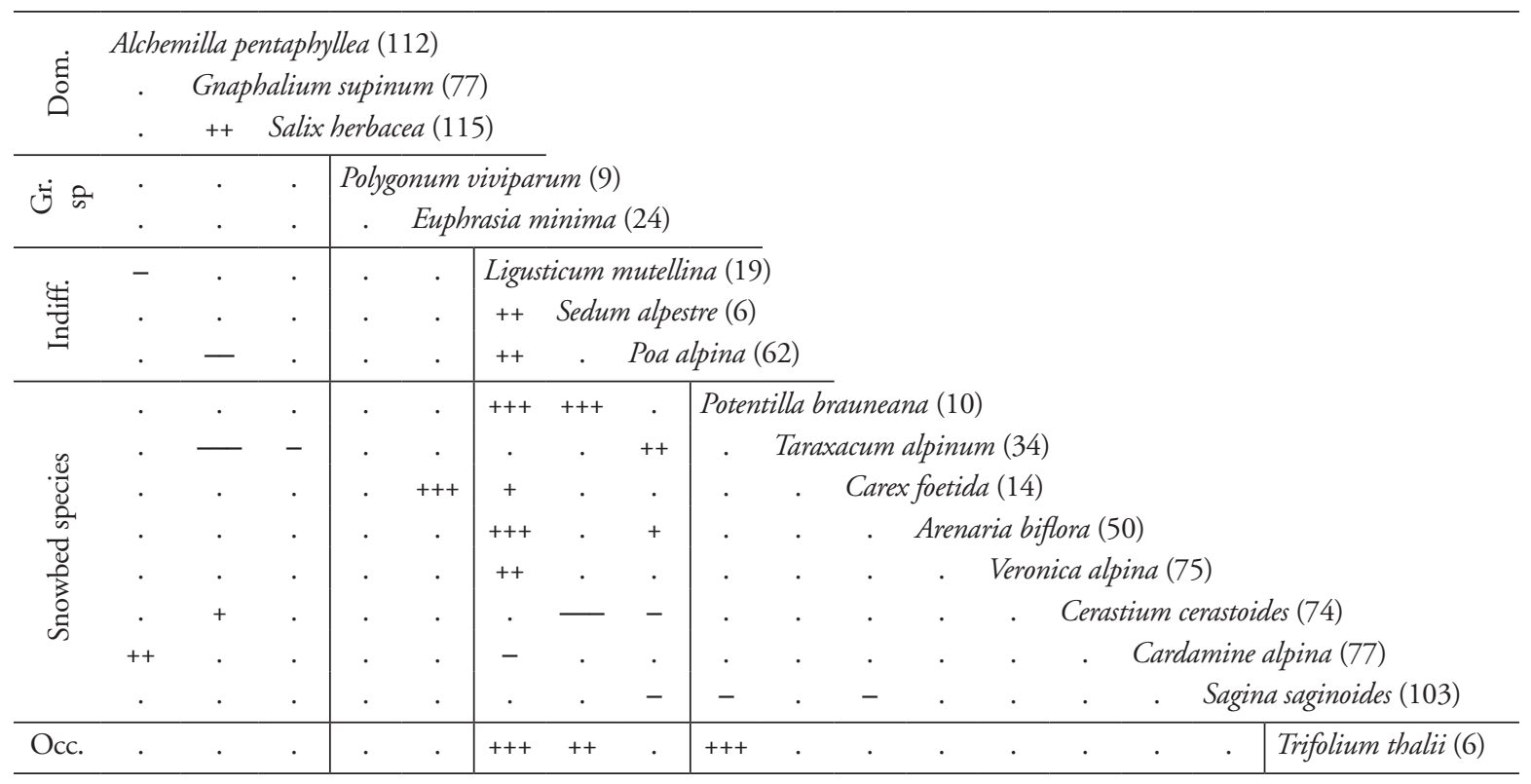

